\title{
The Influence of Vlog on Consumers' Luxury Purchasing Behavior in the Chinese Market-Based on the Theory of Planned Behavior
}

\author{
Danyang He \\ Imperial College Business School
}

\begin{abstract}
In the digital era, more and more industries are taking social media marketing seriously, especially for the luxury industry. They need to build a better relationship with their consumers through social media. Among the various social media, vlogs have become one of the marketing tools that luxury brands have to focus on because of their visual nature that allows consumers to better understand the brand's products. As China is a potential market for luxury goods, this study aims to investigate the impact of vlogs on Chinese consumers' luxury goods purchasing behavior. Based on the theory of planned behavior and the influence of social media on consumers' intention to consume luxuries, this study constructs a model of consumers' behavioral mechanism of purchasing luxury goods, and uses the PLS-SEM modelling algorithm and Smart PLS3.0 software to process and analyze the collected questionnaire data. By comparing the behavioral mechanisms of consumers who have not watched a brand vlog with those who have, the findings show that vlogs have a positive impact on the attitudes, subjective norm and perceived behavioral control of consumers' luxury purchases, with a greatest impact on the subjective norm. The study also shows that the influence subjective norm on intention increases because of vlog. The results of this study can help luxury brands to develop more effective social media marketing strategies to increase consumers'purchase intentions and bring more revenues to luxury brands in the Chinese market.
\end{abstract}

Keywords: Luxury, Vlog, Theory of planned behavior, PLS-SEM.

\section{Introduction}

We have now entered a full-blown digital marketing era, with a wide range of social platforms constantly, emerging and developing. Companies need to constantly adapt, embrace and develop new trends in order to ensure that they are not left behind. With the growth of social platforms such as YouTube in recent years, vlogging has become the new trend (Butler, 2019). According to a study by Cisco, the video will account for $82 \%$ of all internet traffic by 2021, compared to 2016, when this figure was only $73 \%$. Among this video traffic, vlogs make up a large percentage (Source Soft,2020). The vlog is highly interactive and descriptive. It can be used to showcase a company's products and services more visually, to create personalized content for branding, to connect with consumers in a visual way, and to increase the number of searches on the internet for digital marketing (Opusmedia, 2020). According to survey data shared by Hubspot, $90 \%$ of customers in their survey said that product videos helped them make a purchase decision, and $64 \%$ of customers were more likely to purchase a product online after watching a video about it (Bowman, 2017). It is, therefore, significant to study the impact that vlogs on consumer purchasing behavior.

With the continuous improvement of consumers' living standards, luxury goods are gradually consumed by more and more people (Ansarin \& Ozuem,2014). In order to make more mass audience know more about brands, more and more luxury brands have started social media marketing to engage with consumers (Dhaoui, 2014). With the popularity of social media in the luxury industry, it overcomes the contradiction between exclusivity and accessibility of luxury goods by delivering information and interacting with consumers every moment of the day. This helps luxury brands to build brand values at all consumer touchpoints while providing conditions for consumer participatory creativity (Severoni, 2020). Nevertheless, the social media strategy of luxury brands is still slower than in other industries (Elisa, 2018). This is mainly due to the specificity that the luxury industry possesses. How to better close the distance between brands and consumers and achieve the breakthrough of luxury social media strategy is a problem that the luxury industry is facing. Meanwhile, according to Bain's report, China's luxury market doubled its share of total global luxury consumption in 2020 and is expected to become the largest luxury market in the world in 2025 (Lannes \& Zhang, 2020). Therefore, it is meaningful to study the influence of vlogs on consumers' luxury goods purchasing behavior in the Chinese market.

However, the current researches on the influence of vlogs on consumers' luxury purchases mainly focus on the analysis of the factors influencing the purchase intention by the characteristics of vloggers. How vlogs influence consumers' luxury purchases and change their luxury purchasing mechanism need to be further studied. This is the problem that this study is exploring and hoping to solve.

The theory of planned behavior is a powerful model to understand the mechanism of vlog's influence on Chinese consumers' luxury purchasing behavior. The theory of planned behavior explains the process of making decisions after processing various information by measuring individuals' attitudes toward a behavior, subjective norms $\mathrm{t}$, and perceived behavioral control (Ajzen, 1991). These factors, in the form of mediating effects, influence the generation of people's intentions and their final behavioral decisions. This study applies this theory to analyze how vlogs play a role in consumers' decision-making about luxury goods, and to understand how attitudes, subjective norms and perceived behavioral control in the theory of planned behavior are 
influenced by vlogs and gradually affect consumers' intention to purchase luxury goods.

\section{Literature Review}

\subsection{Application of Social Media by Luxury Brands}

Social media is increasingly being used by luxury brands as a new marketing approach. Unlike traditional marketing methods, from the creation of brand content, the dissemination of brand messages and the building of brand image, social media marketing is based on online interaction between brands and consumers (Tsai \& Men, 2013). Kim and Ko's research found that social media marketing has a unique and personalized way of reaching consumers, thus positively influencing them in the communication of luxury brands (Kim \& Ko, 2012).

Kim and Ko also proposed that social media marketing strategy has an impact on consumers' purchase intention through five aspects: entertainment, interaction, trendiness, customization and word of mouth (WOM) (Kim \& Ko, 2012). As for consumer's purchase intention to luxury products, Kin and Ko's study found that an effective social media marketing strategy can lead to positive consumer relationships and thus increase consumers' purchase intention. Of all the influencing factors, social media marketing has the greatest impact on entertainment (Kim \& Ko, 2010).

What more, one of the biggest changes that social media marketing has brought to the luxury industry is that it has changed the marketing logic. Rather than relying on content created by their own marketing departments, luxury brands are actively involving amateurs, KOLs (Key Opinion Leaders), in the marketing of their brands and their products. In this way, luxury brands try to build their brand image among consumers (Alter, 2016). This type of content created and made public by the end consumer is known as User-Generated Content (UGC). According to previous research, user-generated content not only influences consumers' perceptions and choices of brands (Gruen, Osmonbekov, \& Czaplewski, 2006), but also influences consumers' luxury purchases (Blackshaw, 2006). The vlog is a new form of user-generated content in the context of social media development.

\subsection{Theory of Planned Behavior}

The Theory of Planned Behavior (TPB) is a social-cognitive theoretical framework used to explain individuals' decisions to make behavioral intentions after deliberating and processing a variety of information (Ajzen, 1991), and behavioral intentions are a powerful factor in explaining behavior. Attitude toward the behavior refers to the extent to which a person likes or dislikes one of the behavior. Subjective norms refer to the extent to which a person's perception of a behavior is influenced by perceived social pressures, such as whether it is a behavior that is acceptable to most people. This is a social factor. Perceived behavioral control refers to a person's perception of the ease or difficulty of a behavior (Ajzen, 1991). It consists mainly of power of control (the perceived intensity of difficulty) and control beliefs (one's beliefs about the existence of factors that may facilitate or hinder behavioral performance) (Ajzen, 2001). Intention refers to the motivating factor for an individual to perform a behavior and indicates the willingness to perform the behavior (Ajzen, 1991). The theory suggests that the more positive an individual's attitude towards a particular behavior, the stronger the perceived subjective norm and the stronger the perceived behavioral control when making rational decisions, the more obvious the intention to perform the behavior in reality (Ajzen, 1985, 1988).

Theory of planned behavior as a powerful model to explain consumer behavior has been used by several researchers to study consumer buying behavior towards luxury goods. Salem and Chaichi's study found that consumers' attitude, subjective norm and perceived behavioral control were all positively related to their purchase intention (Salem \& Chaichi, 2018). However, there are differences in the impact of these three factors in influencing consumers' purchase intention. Due to the specificity of luxury goods: 'high quality, expensive, rare, prestigious (Tynan, McKechnie \& Chhuon, 2010), perceived behavioral control has an important direct impact on consumers' intentions to purchase luxury goods, especially when consumers considering their household income (Zhang, Cude \& Zhao, 2019). Also perceived behavioral control has a direct impact on consumers' luxury purchases (Jain, Khan \& Mishra, 2017). Studies have found that social media has a positive impact on consumers' attitude, subjective norm and perceived behavioral control (Jinjiri \& Reni, 2018). Vlog as one of the forms of social media, we can draw the following hypothesis:

H1: Vlogs have a positive impact on consumers' attitude, subjective norm, perceived behavioral control in the purchase of luxury products, which ultimately influences consumers' intention to purchase luxuries

\subsection{Influence of Vlog on Consumer's Purchasing Behavior}

Word-of-mouth messages on social media are an important way for consumers to obtain information (Cho \& Jeong, 2013). Chen, Wei and Zhang's study found that source credibility, inspiration and self-congruence have a positive impact on word of mouth and thus influence consumer intentions (Chen, Wei \& Zhang, 2020). The advent of vlogging has helped brands to better realize word of mouth as it has the three factors that have been suggested above as having a positive impact on the word of mouth. Consumers are willing to listen to and accept vloggers because they are more real and closer to their lives than celebrities. Vloggers show their audiences the details of certain products in an impressive way through their videos, helping them to better understand the features of the products.

Hale's research found that the number of views, likes, comments and replies to vloggers' videos positively influenced consumers' perceived credibility and perceived usefulness, and that these two factors directly affected 
consumers' intention to purchase (Hale, 2016). When consumers trust vloggers, and believe in their professionalism and attractiveness, their intention to purchase products recommended by vloggers will increase (Mittal \& Kaur, 2020).

This reflects the social nature of the vlog, which is consistent with the characteristics indicated by the subjective norm in the theory of planned behavior. Based on this the following hypothesis is proposed:

H2: Of the three factors influencing consumers' purchase intention, vlog would have the greatest impact on the subjective norm.

H3: The influence of the subjective norm on consumer purchase intention increases under the influence of the vlog.

\section{Methodology}

\subsection{Research Model}

The following research model of the direct effect was drawn up based on the theory of planned behavior, see Figure 1. This shows the behavioral mechanisms by which consumers make decisions to purchase luxury goods when they are not influenced by the vlog.

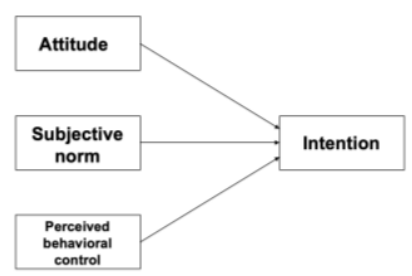

Figure 1: Behavioral mechanism by those who haven't seen luxury's vlog

However, the presence of vlogs can have an impact on consumer intention, and the following model emerges, see Figure 2.

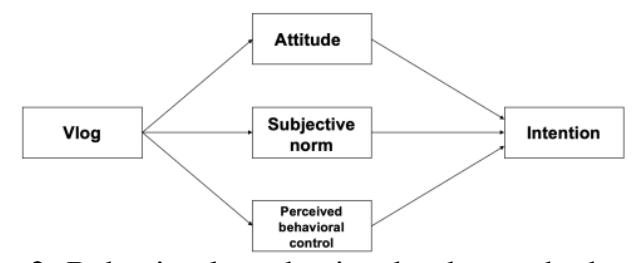

Figure 2: Behavioral mechanism by those who have seen luxury's vlog

Data will be collected for both models: participants who haven't seen some vlogs of luxury brands and participants who have seen. The role of vlogs will be explored by analyzing the effect of vlogs on attitude, subjective norm and perceived behavioral control and by comparing the difference in the mechanisms that influence the final purchase intention between the two groups.

\subsection{Sample and Measurement}

The target participants of this study are consumers who are interested in and have some purchasing power for luxury purchases in the Chinese market, and who also watch vlogs in their daily lives. According to a survey, the number of vlog users in China was 249 million in 2019 (iiMedia Research, 2019). When the margin of error of the survey data is at $5 \%$ and the confidence level is at $95 \%$, required effective sample size of each group is 385. All the questionnaires were conducted on Wenjuanxing, which is a common platform for data collection in China. The questionnaire was distributed on WeChat and Weibo platforms. The data was collected from a random sample of Chinese social media platforms.

This study used a descriptive research survey design and structured closed-ended questionnaire. The questions on measuring the factors that influence consumers' luxury purchase decisions were based on the theory of Ajzen's proposed planned behavior: frequently asked questions, and seven-point bipolar adjective scales were used (Ajzen, 2020). Regarding the impact of vlogs on the three factors affecting purchase intention in the theory of planned behavior, the three main perspectives are measured from the attractiveness of vlog content, relevance to the consumer, and credibility of the vlogger (Chen, Wei \& Zhang, 2020; Lee \& Watkins, 2016). Options 1-7 imply a shift from strongly disagree to strongly agree. The higher the scale, the more the participants agree with the opinion of the question.

In order to ensure the accuracy, reliability and validity of the data, the measures of consumer attitude, subjective norm, perceived behavioral control and intention have been adapted from the concepts in the theory of planned behavior and from existing research, taking into account the attributes of the luxury industry (Table 1).

Table 1: Measurement Item for the model

\begin{tabular}{|c|c|c|}
\hline Variable & Item & $\begin{array}{l}\text { Referen } \\
\text { ce }\end{array}$ \\
\hline \multirow{3}{*}{ Vlog } & $\begin{array}{l}\text { Attractiveness of vlog can change my attitude, } \\
\text { subjective norm and perceived behavioral control } \\
\text { towards luxury purchasing(volog } 1)\end{array}$ & \multirow{3}{*}{$\begin{array}{c}\text { (Chen, } \\
\text { Wei \& } \\
\text { Zhang, } \\
\text { 2020; } \\
\text { Lee \& } \\
\text { Watkins } \\
\text {, 2016) }\end{array}$} \\
\hline & $\begin{array}{l}\text { Congruence of vlog content can change my } \\
\text { attitude, subjective norm and perceived behavioral } \\
\text { control towards luxury purchasing(vlog } 2)\end{array}$ & \\
\hline & $\begin{array}{l}\text { Credibility of vloggers can change my attitude, } \\
\text { subjective norm and perceived behavioral control } \\
\text { towards luxury purchasing(vlog } 3)\end{array}$ & \\
\hline \multirow{4}{*}{ Attitude } & Luxury products are quite appealing to me(AT1) & \multirow{12}{*}{$\begin{array}{c}\text { (Icek } \\
\text { Ajzen, } \\
\text { 2019; } \\
\text { Icek } \\
\text { Ajzen, } \\
\text { 1991; } \\
\text { Ahmad, } \\
\text { Shahar, } \\
\text { Mohd, } \\
\text { Teng, } \\
\text { Manaf, } \\
\text { Sakian } \\
\text { \& Omar, } \\
\text { 2014, } \\
\text { etc.) }\end{array}$} \\
\hline & $\begin{array}{l}\text { Buying luxury products would give me great } \\
\text { satisfaction(AT2) }\end{array}$ & \\
\hline & $\begin{array}{l}\text { Buying luxury products involves more advantages } \\
\text { than disadvantages to me(AT3) }\end{array}$ & \\
\hline & Purchasing luxury products is valuable(AT4) & \\
\hline \multirow{3}{*}{$\begin{array}{l}\text { Subjective } \\
\text { norm }\end{array}$} & $\begin{array}{l}\text { If my friends buy luxury products, I will buy } \\
\text { them(SN1) }\end{array}$ & \\
\hline & $\begin{array}{l}\text { Others around me are possible to recommend } \\
\text { luxury products to me(SN2) }\end{array}$ & \\
\hline & $\begin{array}{l}\text { If vloggers who I often follow recommend luxury } \\
\text { products, I will buy them(SN3) }\end{array}$ & \\
\hline \multirow{3}{*}{$\begin{array}{l}\text { Perceived } \\
\text { behavioral } \\
\text { control }\end{array}$} & $\begin{array}{l}\text { I do not buy luxury products because I feel they are } \\
\text { expensive(PBC1) }\end{array}$ & \\
\hline & $\begin{array}{l}\text { For me, it is easy for me to buy luxury } \\
\text { products(PBC2) }\end{array}$ & \\
\hline & $\begin{array}{l}\text { Whether I buy luxury products is entirely up to } \\
\text { me(PBC3) }\end{array}$ & \\
\hline \multirow[b]{2}{*}{ Intention } & I am willing to buy luxury products(INT1) & \\
\hline & $\begin{array}{l}\text { I have a very high intention of buying luxury } \\
\text { products(INT2) }\end{array}$ & \\
\hline
\end{tabular}

Note*: *Related concepts have been explained in the questionnaire. 
Before the distribution of the questionnaire, a pretest was made among 30 participants to guarantee the clearness and accuracy of the questionnaire.

\subsection{Data Analysis: PLS-SEM (Partial Squares-Structural equation modeling)}

Least

The research adapted to PLS-SEM to make measurements. PLS regression brings together principal component analysis, canonical correlation analysis and multi-variable linear regression. It uses the principle of principal component analysis to condense multiple $\mathrm{X}$ and $\mathrm{Y}$ into components, then analyses the relationship between the respective components of $\mathrm{X}$ and $\mathrm{Y}$ with the help of the principle of canonical correlation analysis, and finally combines the principle of multi-variable linear regression to analyze the relationship between $\mathrm{X}$ for the components of $\mathrm{Y}$, so that the relationship between $\mathrm{X}$ and $\mathrm{Y}$ can be studied. The advantage of PLS Path Modeling is that it can be used to predict complex models with latent variables. At the same time, it can solve the problem of excessive correlation between variables (Henseler, Ringle \& Sinkovics, 2009). Firstly, the measurement of consumer attitudes, subjective norm and perceived behavioral control needs to be measured in several different dimensions. Also based on the model mentioned above, this study adds a new variable of vlog in the theory of planned behavior, which increases the complexity of the model. Furthermore, according to Ajzen's prototype for the theory of planned behavior, intention is determined by people's attitude, subjective norm and perceived behavioral control. These three factors also influence each other (Ajzen, 1991). In order to avoid the influence of these factors on the research results, PLS Path Modeling is a good choice. The software used to analyze the data in this paper is Smart PLS 3.0 software. It is a Java-based application developed by Professor Ringle and his team at the University of Hamburg, Germany.

\section{Data Analysis and Discussion}

\subsection{Descriptive Analysis of Sample Profile}

A total of 831 people participated in this survey. After data screening, 777 of these data were valid. The data recall rate was $93 \%$. The IPs of the participants with valid data came from 27 different provinces in China. Of these 777 valid surveys, 386 people had seen certain luxury brand vlogs and 391 had not. The valid data for both sets of data was about equal and both were greater than 385 (required effective sample size). Of the 777 respondents, there are more women than men. They are mainly aged 18-30 years old and live in first and second tier cities in China. Table 2 and Table 3 show the profile of participants who have not seen the luxury brand vlog (Table 2) and those who have (Table 3) respectively.
Table 2: Profile on those who haven't seen luxury vlogs

\begin{tabular}{|c|c|c|c|}
\hline & Characteristics & Number & Percentage \\
\hline Gender & Female & 280 & $71.6 \%$ \\
\hline & Male & 111 & $28.4 \%$ \\
\hline Age & Below 18 & 7 & $1.8 \%$ \\
\hline & $18-24$ & 138 & $35.3 \%$ \\
\hline & $25-30$ & 123 & $31.5 \%$ \\
\hline & $31-40$ & 78 & $19.9 \%$ \\
\hline Current living cities & Above 40 & 45 & $11.5 \%$ \\
\hline & Tier one & 164 & $41.9 \%$ \\
\hline & Tier two & 143 & $36.6 \%$ \\
\hline & Tier three & 66 & $16.9 \%$ \\
\hline & Others & 18 & $4.6 \%$ \\
\hline
\end{tabular}

Table 3: Profile on those who have seen luxury vlogs

\begin{tabular}{|c|c|c|c|}
\hline & Characteristics & Number & Percentage \\
\hline Gender & Female & 297 & $76.9 \%$ \\
\hline & Male & 89 & $23.1 \%$ \\
\hline Age & Below 18 & 5 & $1.3 \%$ \\
\hline & $18-24$ & 205 & $53.1 \%$ \\
\hline & $25-30$ & 132 & $34.2 \%$ \\
\hline & $31-40$ & 34 & $8.8 \%$ \\
\hline Current living cities & Above 40 & 10 & $2.6 \%$ \\
\hline & Tier one & 186 & $48.2 \%$ \\
\hline & Tier two & 145 & $37.6 \%$ \\
\hline & Tier three & 50 & $13.0 \%$ \\
\hline & Others & 5 & $1.3 \%$ \\
\hline
\end{tabular}

A comparison of the above table shows that the proportion of women participants is larger than those who have not. As for age, among who have seen luxury vlog, the proportion of participants aged 18-30 is bigger, accounting for over $80 \%$ among all ages. But it is smaller in the group of those who have not seen luxury vlogs. In terms of living cities, the difference between the two sets of data is not very large. However, it can be seen that participants living in non-Tier 1 and 2 cities make up a larger proportion of the group that has not watched a vlog.

\subsection{Measurement Model}

The section on measurement model focuses on assessing reliability and validity. Reliability assesses the stability and consistency of the method (Hays \& Revicki, 2005). In PLS-SEM model, the reliability is mainly reflected in the Crobachs Alpha (CA) and Composite Reliability (CR). They explain a construct's internal consistency. The bigger they are, the more reliable the construct is. When both CA and CR are greater than 0.7, the model is proven to have reliability (Hair, Ringle \& Sarstedt, 2011). Table 4 and Table 5 show the values of CA and CR for the two data sets, both of which are greater than 0.7. This indicates that the model is reliable for both data sets.

Table 4: Measurement model results on those who have not seen luxury vlogs

\begin{tabular}{|c|c|c|c|}
\hline Construct & Crobach's alpha & Composite Reliability & AVE \\
\hline Attitude & 0.757 & 0.845 & 0.577 \\
\hline Subjective norm & 0.736 & 0.850 & 0.654 \\
\hline $\begin{array}{c}\text { Perceived behavioral } \\
\text { control }\end{array}$ & 0.709 & 0.838 & 0.633 \\
\hline Intention & 0.801 & 0.909 & 0.833 \\
\hline
\end{tabular}


Table 5: Measurement model results on those who have seen luxury vlogs

\begin{tabular}{|c|c|c|c|}
\hline Construct & Crobach's alpha & Composite Reliability & AVE \\
\hline Vlog & 0.745 & 0.856 & 0.667 \\
\hline Attitude & 0.871 & 0.912 & 0.722 \\
\hline Subjective norm & 0.800 & 0.882 & 0.715 \\
\hline $\begin{array}{c}\text { Perceived behavioral } \\
\text { control }\end{array}$ & 0.801 & 0.884 & 0.719 \\
\hline Intention & 0.876 & 0.942 & 0.890 \\
\hline
\end{tabular}

Validity was also assessed from two perspectives: convergent validity and discriminant validity. Convergent validity was expressed as AVE (Average Variance Extracted) values which means what percentage that latent variable explains on its indicators' variance. And when AVE was greater than 0.5, the model was shown to have convergent validity. Table 4 and Table 5 show the AVE values for both sets of data, with the minimum value being 0.577 . The discriminant validity of the model, showing the distinctive extent to which a construct is different from other constructs follows the Fornell-Larcker criterion. Its logic is that a construct contributes larger variance to its associated indicators comparing with any other construct by comparing the value of the square root of AVE with constructs extracted correlation with other latent constructs. When the values of the square root of AVEs are higher than the constructs' highest correlation, it shows that the model has discriminant validity (Hair, Ringle \& Sarstedt, 2011). Table 6 and Table 7 show the results of discriminant validity based on Fornell-Larcker criterion. The results show that both models have discriminant validity.

Table 6: Results of discriminant validity on those who have not seen luxury vlogs

\begin{tabular}{|c|c|c|c|c|}
\hline & AT & SN & PBC & INT \\
\hline Attitude & $\mathbf{0 . 7 6 0}$ & & & \\
\hline Subjective norm & 0.737 & $\mathbf{0 . 8 0 9}$ & & \\
\hline Perceived behavioral control & 0.615 & 0.675 & $\mathbf{0 . 8 4 1}$ & \\
\hline Intention & 0.751 & 0.747 & 0.795 & $\mathbf{0 . 9 1 3}$ \\
\hline
\end{tabular}

Note*: Diagonal bold text is the root value of AVE. Others are extracted correlations.

Table 7: Results of discriminant validity on those who have seen luxury vlogs

\begin{tabular}{|c|c|c|c|c|c|}
\hline & Vlog & AT & SN & PBC & INT \\
\hline Vlog & $\mathbf{0 . 8 5 1}$ & & & & \\
\hline Attitude & 0.786 & $\mathbf{0 . 9 0 7}$ & & & \\
\hline Subjective norm & 0.840 & 0.759 & $\mathbf{0 . 8 7 3}$ & & \\
\hline Perceived behaviral control & 0.775 & 0.881 & 0.821 & $\mathbf{0 . 9 5 0}$ & \\
\hline Intention & 0.816 & 0.825 & 0.830 & 0.848 & $\mathbf{0 . 9 4 3}$ \\
\hline
\end{tabular}

\subsection{Structural Model}

After verifying the reliability and validity of the model we need to evaluate our model. First, we need to look at the coefficient of determination $\left(\mathrm{R}^{2}\right)$ of the model. $\mathrm{R}^{2}$ measures the percentage of latent variable's variance on total variance. The closer it is to 1 means that the equation explains more about Y. It mainly explains the explanatory power of the model (Hair, Sarstedt, Hopkins \& Kuppelwieser, 2014). For the data set without watching luxury vlogs, the calculated $\mathrm{R}^{2}$ for intention is 0.804 , adjusted to 0.797 . For those who have watched luxury vlogs, the results are shown in Table 8 . When $\mathrm{R}^{2}>0.67$, it demonstrates that coefficient of determination is strong. When $0.33<\mathrm{R}^{2}<0.67$, it shows that coefficient of determination is moderate (Chin, 1998). Our most results are higher than 0.67 , which shows a strongly coefficient determination.

Table 8: Result of $\mathrm{R}^{2}$ on those who have seen luxury vlogs

\begin{tabular}{|c|c|c|}
\hline & $\mathrm{R}^{2}$ & Adjusted $\mathrm{R}^{2}$ \\
\hline Attitude & 0.666 & 0.653 \\
\hline Subjective norm & 0.718 & 0.711 \\
\hline Perceived behavioral control & 0.824 & 0.818 \\
\hline Intention & 0.952 & 0.948 \\
\hline
\end{tabular}

Another value that needs to be verified is $\mathrm{f}^{2}$, which represents effect size. Effect size means a particular exogenous latent variable's relative effectiveness on an endogenous latent variable. It is calculated by the changes in $\mathrm{R}^{2}$.

$\mathrm{f}^{2}$ evaluation $=\left(\mathrm{R}^{2}\right.$ Included $-\mathrm{R}^{2}$ Excluded $) /\left(1-\mathrm{R}^{2}\right.$ Included $)$. It measures the extent of impact of an exogenous latent variable on an endogenous latent variable.

Based on Cohen's research, when $0.02<\mathrm{f}^{2}<0.15$, it representsa small size effect. When $0.15<\mathrm{f}^{2}<0.35$, it represents a medium size effect. When $\mathrm{f}^{2}>0.35$, it represents a large size effect. The results of $\mathrm{f}^{2}$ are shown in Table 9 and Table 10. Among the group who has not seen luxury vlogs, subjective norm has a small effect on intention. Attitude has a medium effect on intention while perceived behavioral control has a large effect on intention. In another group, vlog has large effects on attitude, subjective norm and perceived behavioral control. In addition, these three factors have large effects on intention.

Table 9: Result of $\mathrm{f}^{2}$ on those who have not seen luxury vlogs

\begin{tabular}{|c|c|c|}
\hline & Intention $\left(\mathrm{f}^{2}\right)$ & Interpretation \\
\hline Attitude & 0.193 & Medium effect \\
\hline Subjective norm & 0.045 & Small effect \\
\hline Perceived behavioral control & 0.806 & Large effect \\
\hline
\end{tabular}

Table 10: Result of $\mathrm{f}^{2}$ on those who have seen luxury vlogs

\begin{tabular}{|c|c|c|c|c|c|c|}
\hline & Vlog & AT & SN & $\mathrm{PBC}$ & INT & $\begin{array}{c}\text { Interpre } \\
\text { tation }\end{array}$ \\
\hline Vlog & & 1.62 & 2.552 & 1.503 & & \\
\hline $\begin{array}{l}\text { Attitud } \\
\mathrm{e}\end{array}$ & & & & & 0.388 & $\begin{array}{l}\text { Large } \\
\text { effect }\end{array}$ \\
\hline $\begin{array}{l}\text { Subject } \\
\text { ive } \\
\text { norm }\end{array}$ & & & & & 0.475 & $\begin{array}{l}\text { Large } \\
\text { effect }\end{array}$ \\
\hline $\begin{array}{l}\text { Perceiv } \\
\text { ed } \\
\text { behavio } \\
\text { ral } \\
\text { control }\end{array}$ & & & & & 0.745 & $\begin{array}{l}\text { Large } \\
\text { effect }\end{array}$ \\
\hline $\begin{array}{c}\text { Interpre } \\
\text { tation }\end{array}$ & & $\begin{array}{l}\text { Large } \\
\text { effect }\end{array}$ & $\begin{array}{l}\text { Large } \\
\text { effect }\end{array}$ & $\begin{array}{l}\text { Large } \\
\text { effect }\end{array}$ & & \\
\hline
\end{tabular}

Figure 3 and Figure 4 show the relationship among all variables calculated by PLS-SEM method. The numbers on the lines show the outer loadings for each variable which represent an item's contribution to the assigned construct.

The PLS Algorithm is calculated by using regression to calculate outer loadings and path coefficients for the latent variables after standardizing the values of all observed variables. The regression is then used to estimate location parameters. Then the final factor loadings, path coefficients are calculated. 


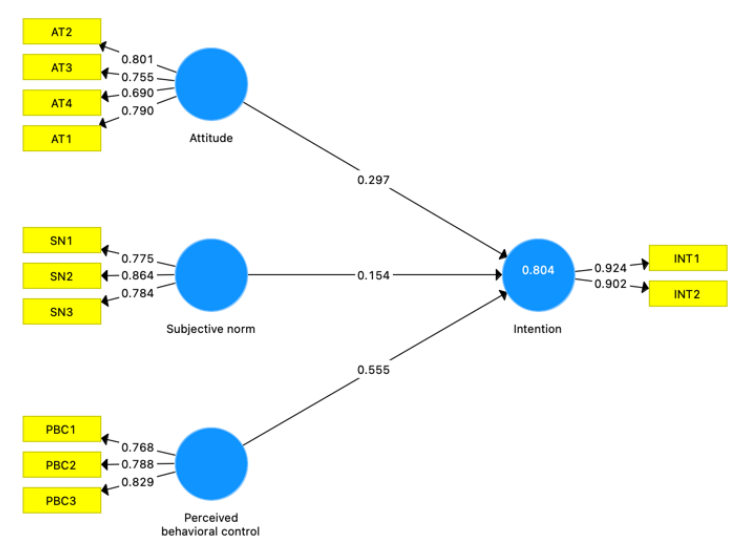

Figure 3: Model of those who have not seen luxury vlogs

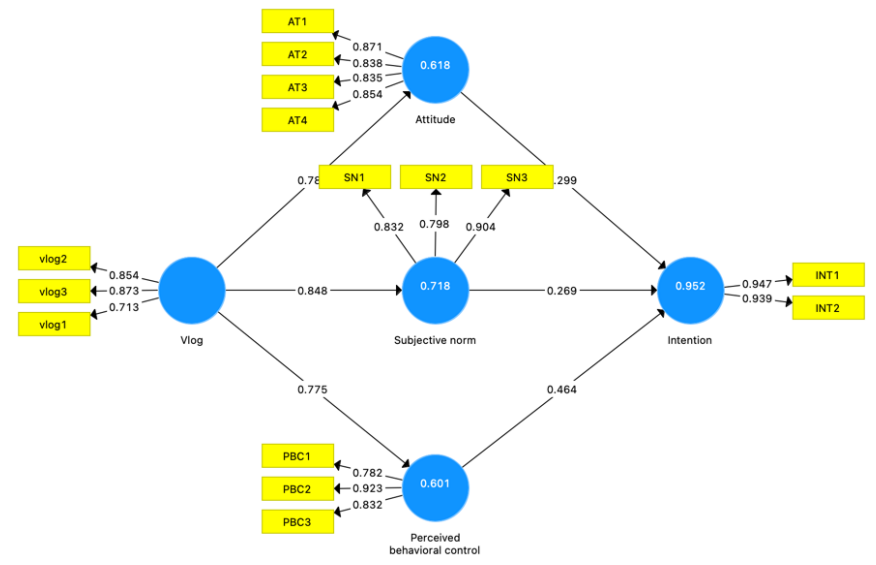

Figure 4: Model of those who have seen luxury vlogs

Following Hair's research, we used bootstrapping with 5000 resamples to assess the model so that we can get the path coefficient. Path coefficient is just like $\beta$ in ordinary least squares regression (Hair, Ringle \& Sarstedt, 2015). Table 11 and Table 12 demonstrate the result of the path coefficient.

Table 11: Structural model results on those who have not seen luxury vlogs

\begin{tabular}{|c|c|c|c|}
\hline & Path Coefficient & T-value & P-value \\
\hline AT-INT & 0.297 & 4.428 & 0.000 \\
\hline SN-INT & 0.154 & 2.212 & 0.035 \\
\hline PBC-INT & 0.555 & 9.849 & 0.000 \\
\hline
\end{tabular}

Table 12: Structural model results on those who have seen luxury vlogs

\begin{tabular}{|c|c|c|c|}
\hline & Path Coefficient & T-value & P-value \\
\hline Vlog-AT & 0.786 & 13.175 & 0.000 \\
\hline Vlog-SN & 0.848 & 18.202 & 0.000 \\
\hline Vlog-PBC & 0.775 & 11.793 & 0.000 \\
\hline AT-INT & 0.299 & 3.905 & 0.000 \\
\hline SN-INT & 0.269 & 4.296 & 0.000 \\
\hline PBC-INT & 0.464 & 5.783 & 0.000 \\
\hline
\end{tabular}

As shown in Table 11, all T-values are higher than 1.96 minimum is 2.112 . And P-values are lower than 0.035 , which is an acceptable result. From the path coefficient, it can be seen that attitude, subjective norm and perceived behavioral control all have a positive effect on consumers' intention to purchase luxury goods among participants who have not seen the vlog. Among them, perceived behavioral control has the greatest impact on consumer's intention to purchase luxury goods. This is mainly due to the specific nature of luxury goods. Consumers need to assess their situations in order to make such decisions.
In Table 12, T-values are all greater than 1.96 (minimum is 3.905 ) and $P$-values are 0.000 , indicating that the results are feasible. From Table 12, we can see that among the participants who have seen the luxury vlog, the effect of vlog on attitude, subjective norm and perceived behavioral control are all positive, while the effect of these three factors on consumers' intention to purchase luxury goods changes compared to those who do not watch the luxury vlog. This confirms our first hypothesis:

H1: vlogs have a positive impact on consumers' attitude, subjective norm, perceived behavioral control in the purchase of luxury products, which ultimately influences consumers' intention to purchase luxuries

Also, we can see that among the effects of vlog on attitude, subjective norm and perceived behavioral control, the largest path coefficient value is 0.848 , the path coefficient of subjective norm. This indicates that vlog has the largest effect on subjective norm. This confirms the second hypothesis:

H2: Of the three factors influencing consumers' purchase intention, vlog would have the greatest impact on the subjective norm.

Comparing Table 11 and Table 12, we can see that the influence of attitude, subjective norm and perceived behavioral control on consumers' intention to purchase luxury goods has changed. Among those who have seen the luxury vlog, perceived behavioral control is still the most influential factor, but it is less influential compared to those who have not seen it. Attitude remained, while subjective norm increased its influence on consumers' luxury purchases. This confirms our third hypothesis:

H3: The influence of the subjective norm on consumer purchase intention increases under the influence of the vlog.

\section{Conclusion and Implications}

The purpose of this study is to investigate how vlogs influence the behavioral mechanisms of Chinese consumers' luxury purchases based on the theory of planned behavior. By comparing data from two groups of consumers (those who have not seen luxury vlogs and those who have), the study identifies how vlogs play a role in Chinese consumers' luxury purchasing behavior. This helps luxury brands develop a more effective social media marketing strategy. Thus, bringing more benefits to the brand.

\subsection{Conclusion}

Based on the data analysis above, we can see that perceived behavioral control has the most influence among the factors that influence Chinese consumers to purchase luxury goods. Consumers need to consider their knowledge of luxury brands and products as well as their individual or household income before considering whether to buy or not (Zhang, Cude \& Zhao, 2019). Vlogs, as a form of social media, have an impact on Chinese consumers' luxury purchase behavior by 
influencing consumers' attitudes, subjective norm and perceived behavioral control over luxury brands, ultimately influencing consumers' intention to purchase luxuries. As a social media, vlogs are characterized by both communication and sharing (CFI, 2020). This reflects the social nature of vlogs. It makes vlog more influential on the subjective norm and also increases the influence of the subjective norm on intention. Vlogger recommendations, especially attractive and convincing vloggers, increase consumers' perception of luxury products. Especially when placed in a social context, vlogs can help increase the value of the act of buying luxury goods. This also increases the consumer's intention to buy luxury goods.

\subsection{Implication}

From a theoretical point of view, this paper extends the application of the theory of planned behavior in the study of consumer behavior. In addition to the original theoretical model, this paper adds vlog as a new variable, aiming to investigate the behavioral mechanism of vlog on consumers' consumption of luxury goods. This also enriches the research on vlogs in the luxury industry. In previous studies, the relationship between vlog and consumers' intention to purchase luxury goods has been analyzed. However, the operational mechanisms involved have not been explored, and through what factors vlog influences consumers' intention to consume luxury goods is the question that this paper aims to address.

The study also has practical implications. The study found that vlogs have a positive impact on consumers' attitude, subjective norm and perceived behavioral control, especially on the subjective norm. For luxury brands, this should be taken into account when developing social media marketing strategies in the Chinese market, especially for vlogs. The influence of vlogs on the subjective norm of consumers should be emphasized. Luxury brands can work with vloggers who have congruence with their target consumers and have physical attractiveness. These vloggers can add recognition and identity to luxury purchases in a social environment. Seeing recommendations from people around them and vloggers they follow will increase their intention to purchase luxury goods. This can bring more benefits to the brand.

\subsection{Limitations and Future research}

In this study, vlog is a more general concept. It ignores the differences in vlogs between brands and the differences in vlog types (e.g. vlogs that recommend products directly and indirectly, etc.). However, in reality, the social media marketing strategies of different luxury brands are different, such as the type of vlogger they work with, the content of the vlog, etc. There are also differences in the impact of different types of vlogs on consumers' intention to buy. These differences can affect the marketing effectiveness of a brand. In future research, further segmentation studies can be conducted on different brands' vlogs to explore the differences in consumers' intention to purchase luxury goods caused by these differences, so that more strategic solutions can be proposed for luxury brands.

\section{References}

[1] Alter, N. (2016) Four ways Instagram is redefining the fashion industry. Available from https://www.launchmetrics.com/resources/blog/four-wa ys-instagram-is-redefining-the-fashion-industry

[Accessed 27 June 2021]

[2] Angella J. Kim \& Eunju Ko (2010). Impacts of Luxury Fashion Brand's Social Media Marketing on Customer Relationship and Purchase Intention. Journal of Global Fashion Marketing, 1(3), 164-171. doi:10.1080/20932685.2010.10593068[Accessed 30 June]

[3] Angella J. Kim \& Eunju Ko (2012) Do social media marketing activities enhance customer equity? An empirical study of luxury fashion brand. Journal of Business Research, 65(10), -. doi: 10.1016/j.jbusres.2011.10.014 [Accessed 2 July 2021]

[4] Ansarin, M., \& Ozuem, W. (2014). Social media and online brand communities. In G. Bowen, \& W. Ozuem (Eds.), Computer-mediated marketing strategies: Social media and online brand communities: Social media and online brand communities (pp. 1-27). Hershey, PA: IGI Global. [Accessed 7 June 2021]

[5] Arrigo Elisa (2018). Social media marketing in luxury brands. Management Research Review, (), MRR-04-2017-0134-. doi:10.1108/MRR-04-2017-0134 [Accessed 9 June 2021]

[6] Bruno Lannes \& Jing Zhang. (2020) China's luxury market in 2020: unstoppable. Available from: https://www.bain.cn/pdfs/202012160302262533.pdf [Accessed 7 May, 2021]

[7] Caroline Tynan, Sally McKechnie \& Celine Chhuon (2010) Co-creating value for luxury brands. Journal of Business Research, 63(11), 1156-1163. doi: 10.1016/j.jbusres.2009.10.012[Accessed 13 June 2021]

[8] CFI (2020) Social media. Available from: https://corporatefinanceinstitute.com/resources/knowled ge/other/social-media/ [Accessed 1 July 2021]

[9] Chedia Dhaoui. (2014) An empirical study of luxury brand marketing effectiveness and its impact on consumer engagement on Facebook. Journal of Global Fashion Marketing, 5(3), 209-222. Doi: http://www.tandfonline.com/action/showCitFormats?do $\mathrm{i}=10.1080 / 20932685.2014 .907605$ [Accessed 7 June 2021]

[10] Chin, W. W. (1998) The partial least squares approach for structural equation modeling. In G. A. Marcoulides (Ed.), Modern methods for business research (pp. 295-336). Lawrence Erlbaum Associates Publishers [Accessed 7 June 2021]

[11] DA Revicki \& Ronald D Hays (2005) Reliability and validity (including reponsiveness). Available from: https://www.researchgate.net/publication/281476115_R eliability_and_validity_including_reponsiveness [Accessed 2 July 2021]

[12] Elisabetta Severoni (2020) Social media marketing in the luxury industry: two successful cases of virtual communities and co-creation. Available from: 
https://www.doxee.com/blog/digital-marketing/socialmedia-in-the-luxury-industry/ [Accessed 4 June 2021]

[13] F. Hair Jr, J., Sarstedt, M., Hopkins, L. and G. Kuppelwieser, V. (2014) Partial least squares structural equation modeling (PLS-SEM): An emerging tool in business research. European Business Review, Vol. 26 No. 2, pp. 106-121. https://doi.org/10.1108/EBR-10-2013-0128 [Accessed 2 July 2021]

[14] Hale Fulya Yüksel 2016) Factors Affecting Purchase Intention in YouTube Videos. Available from: https://www.researchgate.net/publication/313851622_F actors_Affecting_Purchase_Intention_in_YouTube_Vi deos [Accessed 27 June, 2021]

[15] Hazel Butler (2019) 5 Benefits of Starting A Vlog For Your Business. Available from: https://www.acrylicdigital.co.uk/benefits-of-starting-a-v log/ [Accessed 20 June, 2021]

[16] Henseler, J., Ringle, C.M. and Sinkovics, R.R. (2009) The use of partial least squares path modeling in international marketing. Sinkovics, R.R. and Ghauri, P.N. (Ed.) New Challenges to International Marketing (Advances in International Marketing, Vol. 20), Emerald Group Publishing Limited, Bingley, pp. 277-319. Available from: https://doi.org/10.1108/S1474-7979(2009)0000020014 [Accessed 20 June, 2021]

[17] Icek Ajzen (1985) From Intentions to Actions: A Theory of Planned Behavior. In: Kuhl J., Beckmann J. (eds) Action Control. SSSP Springer Series in Social Psychology. Springer, Berlin, Heidelberg. https://doi.org/10.1007/978-3-642-69746-3_2 [Accessed 25 June]

[18] Icek Ajzen. (1991) The Theory of Planned Behavior, Organizational Behavior and Human Decision Process, $50(2)$,

https://doi.org/10.1016/0749-5978(91)90020-T

[Accessed 19 April, 2021]

[19] Icek Ajzen. (2001). Nature and operation of attitudes, Annual Review of Psychology. 52 (1), 27-58, doi: 10.1146/annurev.psych.52.1.27. [Accessed 10 May, 2021]

[20] Icek Ajzen. (2020). The theory of planned behavior: Frequently asked questions. Human Behavior and Emerging Technologies, 2020;1-11. doi:10.1002/hbe2.195 [Accessed 6 May, 2021]

[21] iiMedia. (2019) 2019 China Vlog Business Model and User Usage Behavior Monitoring Report. Available from: https://www.iimedia.cn/c400/64757.html [Accessed 6 May, 2021]

[22] Jung Eun Lee \& Brandi Watkins (2016) YouTube vloggers' influence on consumer luxury brand perceptions and intentions, Journal of Business Research, http://dx.doi.org/10.1016/j.jbusres.2016.04.171

[Accessed 20 April, 2021]

[23] Joe F. Hair, Christian M. Ringle \& Marko Sarstedt (2011). PLS-SEM: Indeed a Silver Bullet. The Journal of Marketing Theory and Practice, 19(2), 139-152. doi:10.2753/mtp1069-6679190202 [Accessed 21 June 2021]

[24] Kabiru Jinjiri Ringim \& Andi Reni. (2019). Mediating Effect of Social Media on the Consumer Buying Behavior of Cosmetic Products, Advances in Economics,
Business and Management Research (AEBMR). 92 DOI:10.2991/icame-18.2019.33 [Accessed 1 May, 2021]

[25] Lini Zhang, Brenda J Cude \& Haidong Zhao (2019) Determinants of Chinese consumers' purchase intentions for luxury goods. International Journal of Market Research, 147078531985367doi:10.1177/1470785319853674 [Accessed 6 July 2021]

[26] Matt Bowman. (2017) Video Marketing: The Future of Content Marketing. Available from: https://www.forbes.com/sites/forbesagencycouncil/201 7/02/03/video-marketing-the-future-of-content-marketi $\mathrm{ng} / \mathrm{sh}=3463 \mathrm{f} 3806 \mathrm{~b} 53$ [Accessed 7 May 2021]

[27] Mittal, E.., \& Kaur, N. (2020). Do YouTube Vlogs Influence Purchase Intention? The Mediation Role of Perceived Source Credibility. Ramanujan International Journal of Business and Research, 5, 37-53. Doi https://doi.org/10.51245/rijbr.v5i1.2020.215 [Accessed 30 June 2021]

[28] Mohamad Hasnan Ahmad, Suzana Shahar, Nur Islami Mohd, Fahmi Teng, Zahara Abdul Manaf, Noor Ibrahim Mohd Sakian \& Baharudin Omar (2014). Applying theory of planned behavior to predict exercise maintenance in sarcopenic elderly. Clinical Interventions in Aging, 2014(9), 1551-1561. doi:10.2147/CIA.S60462

[29] Opus Media. (2020) The importance of vlogging. Available from: https://weareopusmedia.com/blogs/the-importance-of-v logging/ [Accessed 7 May 2021].

[30] Pete Blackshaw. (2006) The Consumer-Controlled Surveillance Culture. Available from: https://www.clickz.com/the-consumer-controlled-survei llance-culture/69332/ [Accessed 4 May 2021].

[31] Sheetal Jain, Mohammed Naved Khan \& Sita Mishra (2017) Understanding consumer behavior regarding luxury fashion goods in India based on the theory of planned behavior, Journal of Asia Business Studies, Vol. 11 Iss 11 pp. doi: http://dx.doi.org/10.1108/JABS-08-2015-0118 [Accessed 23 June, 2021]

[32] Source Soft Solutions Pvt. Ltd. (2020) Vlogging: How It Can Help Your Business. Available from: https://www.sourcesoftsolutions.com/vlogging-how-it-c an-help-your-business/ [Accessed 8 May 2021]

[33] Suha Fouad Salem \& Kamelia Chaichi (2018) Investigating causes and consequences of purchase intention of luxury fashion. Management Science Letters, 8 (2018), 1259-1272. doi: 10.5267/j.msl.2018.10.001[Accessed 17 June 2021]

[34] Thomas W. Gruen, Talai Osmonbekov \& Andrew J. Czaplewski (2006). eWOM: The impact of customer-to-customer online know-how exchange on customer value and loyalty. Journal of Business Research, 59(4), 0-456. doi: 10.1016/j.jbusres.2005.10.004 [Accessed 5 May, 2021]

[35] Wan-Hsui Sunny Tsai \& Linjuan Rita Men. (2013) Motivations and Antecedents of Consumer Engagement with Brand Pages on Social Networking Sites. Journal of Interactive Advertising, 13(2), 76-76. Doi: https://doi.org/10.1080/15252019.2013.826549 [Accessed 2 July 2021] 
[36] Yusi Cheng, Wei Wei \& Lu Zhang (2020). Seeing destinations through vlogs: implications for leveraging customer engagement behavior to increase travel intention. International Journal of Contemporary Hospitality Management, ahead-of-print(ahead-of-print), doi:10.1108/IJCHM-04-2020-0319[Accessed 2 July 2021]

\section{Author Profile}

Danyang He is studying at Imperial College Business School for MSc of Strategic Marketing program. She received her bachelor degree of Journalism from Beijing Foreign Studies University in 2020. She has rich experience in different industries on social media operation, like Xinhua News Agency (official press agency of China), Tencent (a world-leading internet and technology company) and Ogilvy. 